\title{
Conforto térmico e desempenho de pintos de corte submetidos a diferentes sistemas de aquecimento no período de inverno
}

\section{Marcelo Bastos Cordeiro ${ }^{1}$, Ilda de Fátima Ferreira Tinôco ${ }^{1}$, Jadir Nogueira da Silva ${ }^{1}$, Ricardo Brauer Vigoderis ${ }^{2}$, Francisco de Assis de Carvalho Pinto ${ }^{1}$, Paulo Roberto Cecon ${ }^{3}$}

\author{
${ }^{1}$ Departamento de Engenharia Ambiental - UFV, Campus Universitário, Viçosa, MG. \\ 2 UFRPE - Unidade Garanhuns. \\ ${ }^{3}$ Departamento de Informática - UFV.
}

RESUMO - Avaliou-se o efeito de três sistemas de aquecimento de aviários no conforto térmico e no desempenho de pintos de corte criados no inverno na Região Sul do Brasil. Utilizaram-se três galpões avícolas com 17.700 aves (Cobb) por galpão, em dois lotes de criação. Os sistemas de aquecimento avaliados foram: fornalha a lenha (aquecimento indireto do ar); campânulas infravermelhas a gás; e tambores de aquecimento por radiação com aquecimento suplementar de campânulas infravermelhas a gás. Para avaliação do ambiente térmico e do desempenho animal, foi utilizado delineamento em blocos casualizados, com três sistemas de aquecimento, em dois lotes de criação. Nas duas primeiras semanas de vida das aves, o sistema de tambor + campânulas é o mais eficiente em manter a temperatura e umidade relativa do ar na condição de conforto térmico das aves. Consequentemente, propicia melhores ganho de peso, conversão alimentar e eficiência produtiva.

Palavras-chave: ambiência animal, avicultura de corte, pintinhos

\section{Thermal comfort and performance of chicks submitted to different heating systems during winter}

\begin{abstract}
The objective of this study was to evaluate the effect of different poultry house heating systems on the thermal comfort and performance of broiler chicks during the winter period, in the southern region of Brazil. Three buildings were used, each containing 17,700 broiler chickens (Cobb), during two complete productive cycles. Three heating systems were evaluated: furnace with indirect air heating; infrared heater and radiant experimental "drum” system with an infrared supplemental heating system. In order to evaluate the thermal environment and animal performance, a randomized block experimental design with three heating system was used, in two complete productive cycles. In the first two weeks after birth, the radiant experimental "drum" system is the most efficient in maintaining the air temperature and relative humidity in thermal comfort condition of the broiler chicks and, consequently, result in the best results of weigh gain, dietary conversion and efficient production.
\end{abstract}

Key Words: animal environment, broiler chicks, poultry

\section{Introdução}

O Brasil é o país com o maior número de informações relativas ao acondicionamento térmico de instalações avícolas abertas para as condições de verão em clima tropical (Tinôco et al., 2004). Contudo, ainda há muita carência de investigações acerca do gasto energético e da eficiência dos sistemas de aquecimento, bem-estar animal e níveis de contaminação do ar para as condições arquitetônicas e construtivas dos galpões avícolas brasileiros. Essa disparidade é preocupante, tendo em vista as exigências cada vez maiores do mercado consumidor internacional frente às questões humanitárias de criação e bem-estar animal, que incluem o conforto térmico e a preservação ambiental com enfoque no tipo de combustível e consumo de energia. A não atenção a estas questões pode resultar em problemas sérios à exportação brasileira, especialmente para a Europa.

As duas primeiras semanas de vida das aves são as mais críticas, pois erros cometidos nesta fase não poderão ser corrigidos a contento no futuro, afetando assim o desempenho final das aves (Miller, 1996; Butcher \& Nilipour, 2002).

Desta forma, para atender as exigências de conforto térmico das aves, o aquecimento é fundamental no início da vida e dele depende o bom desenvolvimento animal (Tinôco, 2001). No inverno, esse item merece atenção 
redobrada, pois é maior a necessidade energética para suprir a diferença entre a temperatura ideal para os pintos e a temperatura ambiente externa.

Aquecer um aviário não é uma tarefa fácil no Brasil, uma vez que as instalações são abertas e sem nenhum isolamento térmico (Tinôco, 1995). Desta forma, o gasto de energia para o aquecimento do ar dos ambientes onde estão alojados os pintinhos é sempre maior que nos galpões isolados. É importante considerar que basicamente todos os sistemas de aquecimento do ar no interior de um galpão envolvem a queima de combustíveis e consequentes emissões de gases poluentes, alguns extremamente nocivos às aves, ao trabalhador e à atmosfera.

Segundo Abreu \& Abreu (2002), vários tipos de aquecedores foram desenvolvidos para fornecer calor e proporcionar conforto térmico às aves com menor consumo de energia. Vários fatores devem ser considerados na escolha de um sistema de aquecimento, entre eles, a temperatura ambiente requerida para cada idade, a taxa de ventilação, a perda de calor pelos constituintes da instalação, o dimensionamento e o número de aquecedores necessários (Baêta \& Souza, 1997).

Esta pesquisa foi realizada com o objetivo de avaliar o efeito de diferentes sistemas de aquecimento de aviários no conforto térmico e no desempenho zootécnico de pintos de corte criados no período de inverno na Região Sul do Brasil.

\section{Material e Métodos}

A pesquisa foi realizada com frangos de corte no período de julho a outubro de 2005, em uma propriedade avícola comercial integrada, localizada a uma altitude de 750 m, com temperatura média anual de 16 a $17^{\circ} \mathrm{C}$ e tipo climático Cfb - temperado (mesotérmico úmido e verão ameno), segundo sistema proposto por Köppen (Critchfield, 1974).

No experimento foram utilizados três galpões avícolas representativos do padrão adotado pela empresa, com dimensões idênticas (12,0 × 100,0 × 3,0 m) e mesma orientação cartográfica (leste-oeste), situados em mesmo núcleo de criação e distantes 30,0 m entre si. Os galpões possuíam forros de polietileno, posicionados a 3,0 m de altura, laterais teladas e protegidas por duplo cortinado de poliuretano e muretas de 0,10 m de altura. A cobertura era de telhas cerâmicas, com inclinação de $30 \%$ e beiral de 0,50 m.

Os galpões foram equipados com bebedouros do tipo nipple com aparador de gotas e comedouros do tipo tubular infantil para a fase inicial das aves e, na fase de crescimento e engorda, do tipo automático. Na fase inicial, duas primeiras semanas de vida, as aves foram confinadas numa área correspondente a $1 / 3$ do total do galpão
(33,0 × 12,0 m), protegida com cortinas de lona plástica para reduzir o volume de ar a ser aquecido.

Em cada galpão, foi instalado um dos sistemas de aquecimento: fornalha a lenha (aquecimento indireto do ar); campânulas infravermelhas a gás; e tambores de aquecimento por radiação associados a campânulas infravermelhas a gás.

O sistema de aquecimento com fornalha a lenha consistiu de fornalha de formato cilíndrico (largura de 1,56 $\mathrm{m}$, comprimento de 2,60 m e altura de 1,65 m), de material metálico e revestida por isolante térmico. $\mathrm{O}$ ar aquecido na fornalha era levado para um sistema de distribuição composto por 42,0 m de tubulação metálica colocada na parte interna central do galpão. A tubulação possuía orifícios a cada 1,0 m para a saída do ar aquecido. A vazão de ar aquecido era de $2.550 \mathrm{~m}^{3} /$ hora a uma temperatura de $220^{\circ} \mathrm{C}$ na saída da fornalha.

No sistema de aquecimento com campânulas infravermelhas, foram utilizadas 14 campânulas infravermelhas a gás, posicionadas a 1,10 $\mathrm{m}$ da cama, fazendo ângulo de $45^{\circ}$ com o plano horizontal, distribuídas de maneira alternada e equidistantes ao longo da área destinada às aves na sua fase inicial.

No sistema de aquecimento com tambores, foram colocados quatro tambores de aquecimento por radiação, feitos artesanalmente com tambores de 200 litros. Cada tambor, posicionado com o eixo maior na horizontal, apoiava-se em suportes metálicos, de forma a garantir afastamento de 0,70 $\mathrm{m}$ da cama, impedindo contato direto com as aves. Uma de suas extremidades possuía abertura para a colocação do combustível (lenha) e a extremidade oposta possuía chaminé para saída dos gases de combustão para fora do galpão. Esse sistema era complementado com campânulas, acionadas automaticamente por termostatos.

Para caracterizar o ambiente térmico, foram tomadas as medidas diárias de temperatura e umidade relativa do ar em três pontos de cada galpão, respectivo ao comprimento dos galpões (Figura 1). As medições foram realizadas a uma altura compatível com a zona de ocupação dos pintinhos a $10,0 \mathrm{~cm}$ da cama, em intervalos de 15 minutos, durante todo o período experimental. Foram utilizados dataloggers T/HR da marca Testo, modelo H1, com resolução de $0,1^{\circ} \mathrm{C}$ (temperatura) e $1 \%$ (umidade), e acurácia de $\pm 0,5{ }^{\circ} \mathrm{C}$ (temperatura) e $\pm 1 \%$ (umidade).

Utilizaram-se 17.700 aves de corte por galpão, linhagem comercial Cobb-Vantress, pertencentes ao mesmo matrizeiro, originados do incubatório da própria empresa. Todo o processo de embarque e desembarque das aves obedeceu ao mesmo procedimento e horário para todos os galpões. 


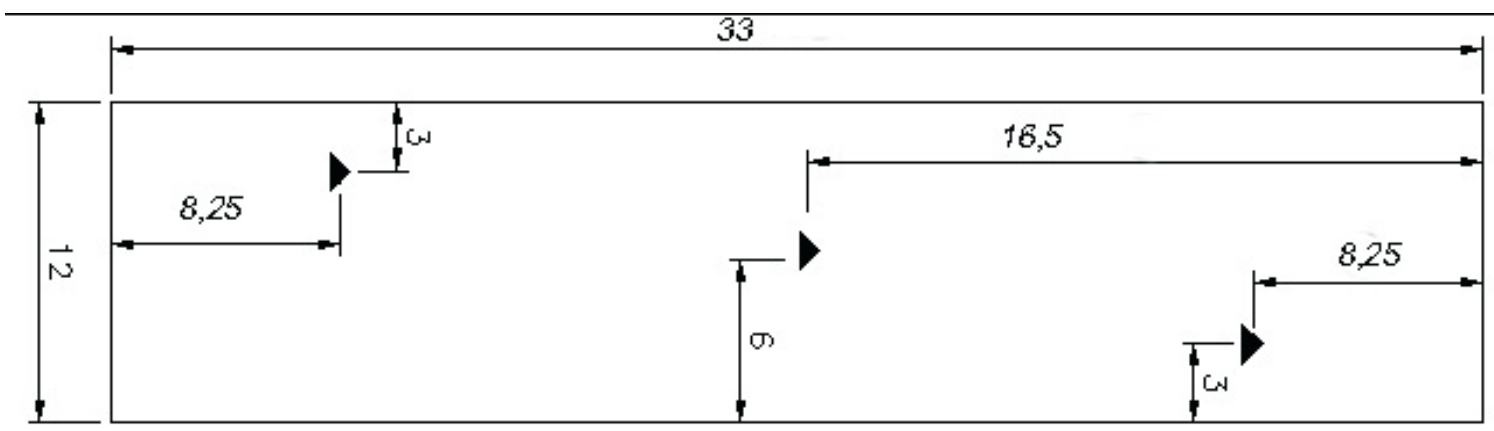

Figura 1 - Disposição dos sensores no interior das instalações para registro dos dados no fase inicial das aves.

As dietas fornecidas aos animais foram formuladas com base nas exigências de nutrientes para as diferentes fases de crescimento, estabelecidas pelo setor de agropecuária da Perdigão Agropecuária e foram iguais para todos os sistemas.

As variáveis avaliadas para determinação do desempenho zootécnico foram consumo de ração, ganho de peso, conversão alimentar, eficiência produtiva, mortalidade e consumo de água. Na determinação do ganho de peso, as aves (amostragens relativas a 0,5\%) foram pesadas no primeiro dia de vida e no final de cada semana subsequente ao ciclo de produção correspondente às fases de crescimento. Foi feita a leitura diária de hidrômetros instalados em cada galpão para cálculo do consumo de água.

Para estudo das variações de temperatura do ar $\left({ }^{\circ} \mathrm{C}\right)$ e umidade relativa (\%) entre os sistemas de aquecimento, o experimento foi disposto em esquema de parcelas subdivididas. Cada parcela foi composta por um dos sistemas e as subparcelas, pelos horários (96 horários) em que foram realizados os registros.

No estudo do desempenho animal, os sistemas foram dispostos num esquema de parcelas subdivididas, de modo que cada parcela foi composta por um dos sistemas de aquecimento e as subparcelas, pelas semanas de observação.

O delineamento experimental utilizado, tanto nas avaliações das variáveis ambientais como nos dados de desempenho animal, foi em blocos casualizados, com duas repetições correspondentes aos lotes de produção.

\section{Resultados e Discussão}

Na primeira semana de vida dos pintinhos, o sistema de aquecimento com tambor + campânulas diferiu estatisticamente dos demais (Figura 2), pois promoveu os maiores valores de temperatura do ar $\left({ }^{\circ} \mathrm{C}\right)$, entretanto manteve a temperatura na faixa de conforto das aves apenas no horário de 13 e 14h30. De acordo com recomendações na literatura (Tinôco, 2001; Macari et al., 2004; Ferreira, 2005; Medeiros et al., 2005), a temperatura para a faixa de conforto na primeira semana de vida das aves situa-se entre 32 e $34^{\circ} \mathrm{C}$.

O conforto térmico nas primeiras semanas das aves é importante por diminuir o efeito das variações térmicas do ambiente sobre o aparelho respiratório dos pintos, uma vez que o ar com baixa temperatura deve ser aquecido nas vias respiratórias para que a troca gasosa nos pulmões seja eficiente (Franco \& Fruhauff, 1997). Quando submetido à temperatura abaixo da zona de conforto, o animal destina parte da energia ingerida para gerar calor para manutenção da temperatura corporal, o que leva à redução da produtividade (McDowell, 1974).

O sistema de aquecimento com campânulas apresentou maior amplitude entre a temperatura média máxima e temperatura média mínima na primeira semana de vida das aves e essa variação foi de $5,85^{\circ} \mathrm{C}$. Os sistemas de fornalha a lenha e tambores + campânulas apresentaram amplitude térmica de $5,03{ }^{\circ} \mathrm{C}$. Entretanto, para todos os sistemas, os valores de amplitude térmica encontrados não foram prejudiciais às aves na sua fase inicial, que, segundo Furlan (2006), é de $6{ }^{\circ} \mathrm{C}$. Segundo Nääs et al. (2001), a maior amplitude térmica dentro do galpão pode trazer sérios prejuízos às aves.

Na segunda semana de vida das aves (Figura 2), o sistema de tambores + campânulas manteve a temperatura do ar $\left({ }^{\circ} \mathrm{C}\right)$ na faixa de conforto térmico das aves entre as $9 \mathrm{~h}$ e 18h30. No sistema de campânulas a gás, os valores de temperatura mantiveram-se na faixa de conforto somente entre $14 \mathrm{~h} \mathrm{e} 17 \mathrm{~h}$. No sistema de fornalha a lenha, em nenhum momento foi alcançada a faixa de conforto, de 28 a $32{ }^{\circ} \mathrm{C}$, recomendada na literatura. Nesse sistema, ocorreu a maior variação entre a temperatura média máxima e mínima, com amplitude de $5,44{ }^{\circ} \mathrm{C}$ (Figura 2). No sistema de fornalha a lenha, foi observada a menor amplitude térmica $\left(3,95^{\circ} \mathrm{C}\right)$, seguido do sistema de tambores + campânulas, cuja amplitude térmica foi de $4,12{ }^{\circ} \mathrm{C}$. Entretanto, para todos os sistemas de 
aquecimento avaliados, os valores de amplitude térmica não foram prejudiciais às aves na sua fase inicial.

O pintinho possui grande relação entre área/volume corporal, o que dificulta a retenção do calor corporal (Baeta \& Souza, 1997) e, como sua capacidade de termorregulação não estar bem desenvolvida, as aves jovens necessitam de temperaturas mais elevadas para manter sua temperatura corporal constante (Teeter, 1986). Se a temperatura se encontra abaixo das exigências térmicas das aves, grande parte da energia ingerida na ração que poderia ser utilizada para produção é desviada para manutenção do sistema termorregulador. Temperaturas acima do conforto térmico dos pintinhos podem induzir hipertermia com desidratação, levando a redução no consumo de ração e atraso no crescimento (Mickelberry et al., 1966), enquanto temperaturas muito abaixo da zona de conforto podem desencadear quadros hipotérmicos e induzir a síndrome da hipertensão pulmonar (ascite) em frangos de corte (Maxwell \& Robertson, 1997).

A amplitude térmica externa na segunda semana de vida das aves foi de $8,89^{\circ} \mathrm{C}\left(11,79-20,68^{\circ} \mathrm{C}\right)$, superior à amplitude térmica da primeira semana, de $7,82^{\circ} \mathrm{C}\left(13,20-21,02^{\circ} \mathrm{C}\right)$. Isso indica que as condições climáticas do ambiente externo foram muito mais severas na segunda semana de vida das aves, o que exige maiores cuidados em relação ao ambiente térmico no interior dos pinteiros.

Na primeira e segunda semanas de vida das aves, os menores valores de umidade relativa (\%) foram observados no sistema de tambor + campânulas (Figura 3). Segundo Tinôco et al. (2004), em ambientes com umidade relativa de $70 \%$, as aves ficam mais sensíveis ao estresse térmico.

No sistema de aquecimento com tambor + campânula, a umidade relativa do ar (\%) se manteve, na maioria dos horários de observação da primeira semana de vida das aves, dentro da faixa de 50 a $70 \%$, valores recomendados por Reece \& Lott (1982) e Tinôco (2001). Nesse sistema, foi observada a pior condição de umidade relativa (\%) e os menores valores ( $<50 \%$ ) foram observados entre $4 \mathrm{~h} 45$ e $7 \mathrm{~h} 45$ e $10 \mathrm{~h} 15$ e $20 \mathrm{~h} 45$, totalizando 13 horas e 30 minutos de desconforto com relação à condição de umidade relativa. Na segunda semana de vida dos pintinhos, esse sistema proporcionou valores de umidade relativa dentro da faixa desejável.

Valores de umidade relativa do ar muito abaixo do recomendado podem causar desidratação das mucosas dos pintinhos nas primeiras semanas de vida e aumentar os riscos de doenças cardíacas e pulmonares no futuro (Baião et al., 1998). Na primeira semana de vida das aves, houve atraso na resposta do comportamento da curva de umidade relativa do ar do ambiente dos sistemas (interior dos aviários) em relação ao ambiente externo, de modo que, quando a umidade relativa do ar externo começou a decair no período da manhã (por volta das $8 \mathrm{~h}$ ), a umidade relativa do ar dos aviários demorou cerca de duas horas (por volta das $10 \mathrm{~h}$ ) para acompanhar esse declínio, provavelmente em virtude do rápido aumento da temperatura externa, pois, das
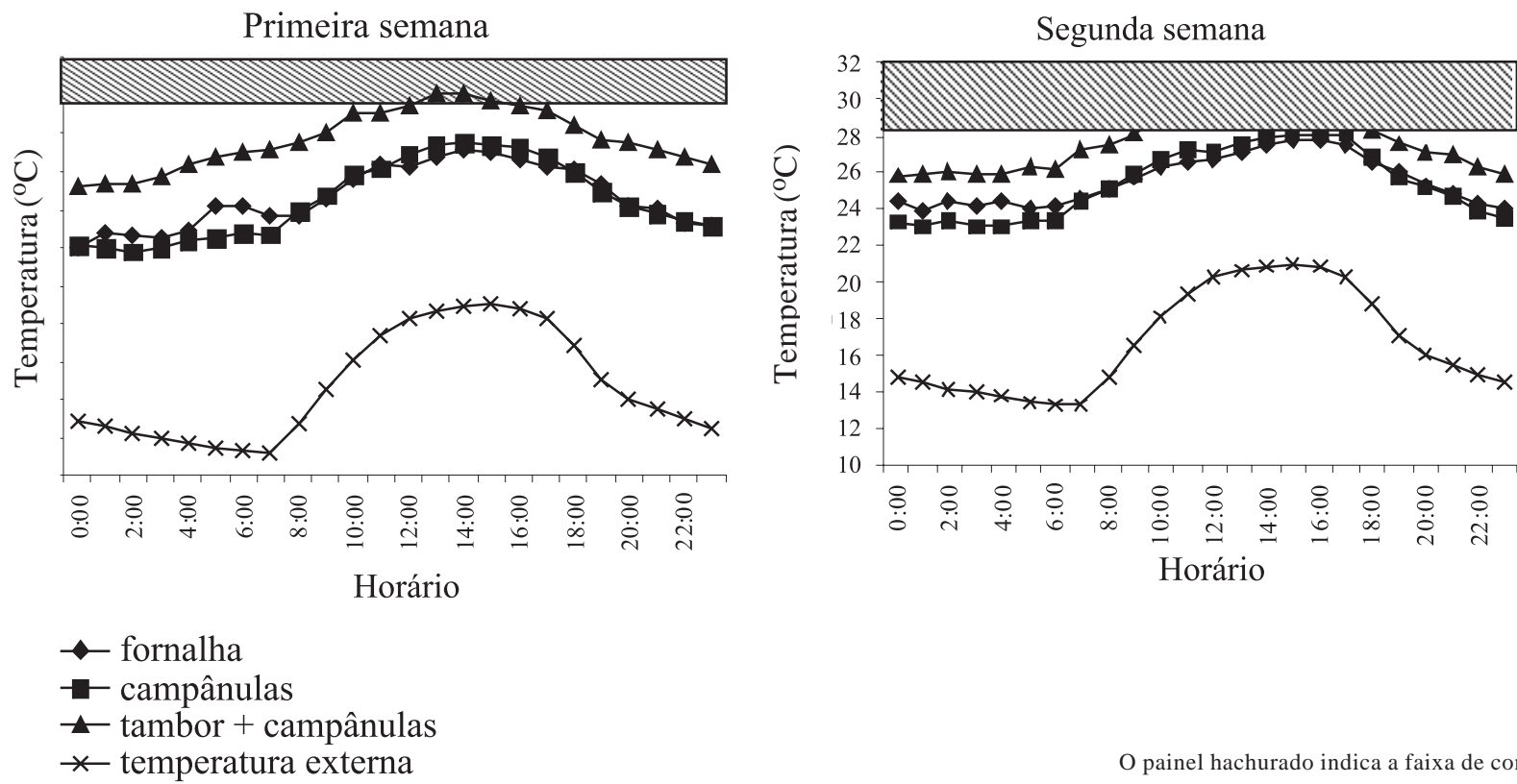

O painel hachurado indica a faixa de conforto térmico.

Figura 2 - Valores médios da temperatura do ar na primeira e segunda semanas de vida de aves submetidas a três sistemas de aquecimento.

R. Bras. Zootec., v.39, n.1, p.217-224, 2010 

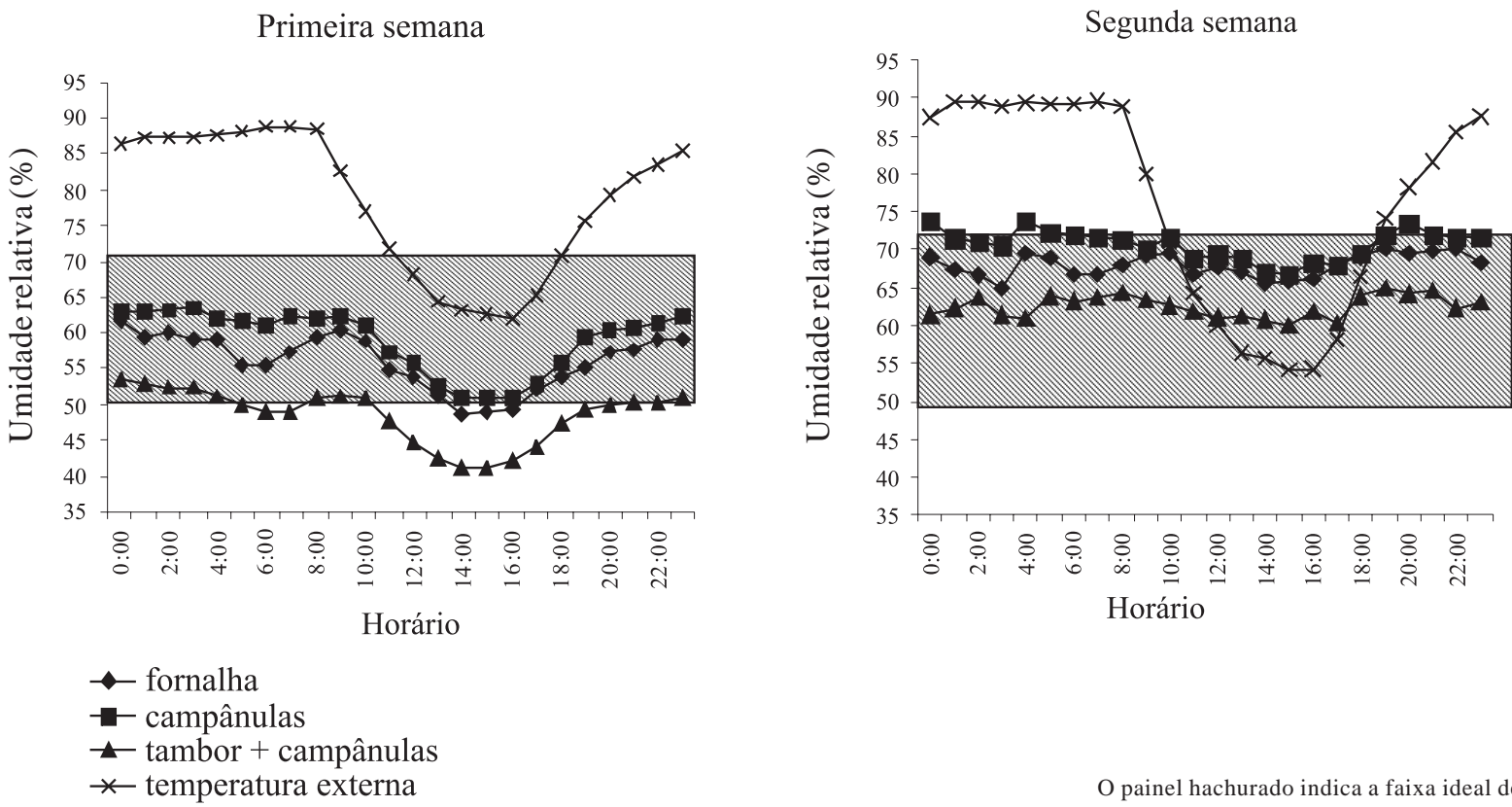

Horário

O painel hachurado indica a faixa ideal de umidade.

Figura 3 - Umidade relativa do ar na primeira e segunda semanas de vida de aves submetidas a três sistemas de aquecimento.

$8 \mathrm{~h}$ às $10 \mathrm{~h}$, esse aumento foi de $3,38^{\circ} \mathrm{C}$, enquanto no mesmo período o aumento da temperatura do ar no interior dos aviários foi de $1,35^{\circ} \mathrm{C}$ nos sistemas de aquecimento com fornalha a lenha e com tambor+campânula e de $1,81^{\circ} \mathrm{C}$ no sistema de campânulas a gás. Esse atraso pode ser explicado pelo amortecimento e inércia térmica do envoltório (materiais de construção e fechamento dos galpões).

Na segunda semana, no sistema de aquecimento com campânulas a gás, os valores de umidade relativa foram superiores a 70\% na maioria dos horários. Nesse tipo de sistema de aquecimento, é comum encontrar gotejamento de água das cortinas, ocasionado pela condensação do vapor d’água. Oliveira et al. (2006) constataram que, no período de 1 a 21 dias de idade, o aumento da umidade relativa influenciou $(\mathrm{P}<0,05)$ negativamente a conversão alimentar das aves expostas ao ambiente de calor, evidenciando que, conforme o ambiente térmico no qual a ave é mantida, é fundamental que, além da temperatura, outros elementos meteorológicos, como a umidade relativa do ar, sejam mensurados por influenciarem a manutenção de sua homeotermia, uma das funções vitais mais importantes das aves (Tinôco, 2004).

Os dois elementos meteorológicos temperatura e umidade são altamente correlacionados ao conforto térmico animal, uma vez que, em temperaturas muito elevadas, o principal meio de dissipação de calor das aves é a evaporação, que depende da umidade relativa do ar (Baêta \& Souza, 1997).
Na segunda semana, a amplitude da umidade relativa (\%) do ambiente externo foi de 36,64\% (53,78 - 90,42\%), superior à da primeira semana, que foi de $27,57 \%(61,89$ $89,46 \%$ ), confirmando que, junto com os baixos valores de temperatura externa, a segunda semana de vida dos animais piorou as condições a serem enfrentadas pelos sistemas de aquecimento.

As aves, por serem homeotérmicas, produzem calor constantemente, porém, em baixas temperaturas, aumentam a produção de calor, de umidade e do dióxido de carbono como subprodutos de sua atividade biológica (Curtis, 1983). Na zona de conforto, a taxa metabólica é mínima e a homeotermia é mantida com menos gasto energético; assim, na zona de termoneutralidade, a fração de energia metabolizável utilizada para a termogênese é mínima e a energia líquida de produção é máxima (Macari et al., 1994).

Na primeira semana, não houve diferença no consumo de ração (kg/ave) e no ganho de peso entre os sistemas de aquecimento. Entretanto, houve diferença na conversão alimentar das aves nos sistemas de tambor + campânula e no sistema de fornalha a lenha; a melhor eficiência produtiva foi observada no sistema de tambor + campânulas (Tabela 1).

Na primeira semana de vida das aves, nos sistemas de fornalha a lenha e campânulas infravermelhas, não houve aquecimento adequado dos pintinhos, pois os valores de temperatura ficaram abaixo da zona de conforto térmico. Apesar de o sistema de tambor + campânula ter sido o único em que foi possível alcançar temperaturas adequadas 
ao bem-estar das aves, essas temperaturas se mantiveram durante pequeno período de tempo (13 h - 14h30).

A maior taxa de formação de órgãos vitais, como coração, pulmão, sistema digestivo e imunológico, ocorre durante os primeiros 7 dias de vida dos pintos (Funck \& Fonseca, 2008). Para que esse desenvolvimento seja normal, os pintos necessitam absorver todos os nutrientes e anticorpos contidos no saco embrionário e isso só ocorre se forem mantidos em condições ideais de temperatura e umidade e ingerirem água e ração (Funck \& Fonseca, 2008).

Diversos estudos têm demonstrado que o desempenho das aves está intimamente relacionado às condições térmicas do ambiente. O consumo de ração e o ganho de peso são influenciados negativamente pela temperatura ambiente (Abreu et al., 2000; Lana et al., 2000; Oliveira et al., 2006; Faria Filho et al., 2006).

Na segunda semana de vida, as aves mantidas no sistema de aquecimento com fornalha a lenha apresentaram os maiores valores médios de consumo de ração, diferindo estatisticamente dos demais sistemas. No sistema de tambor + campânula, foram observados os melhores resultados de ganho de peso, conversão alimentar e eficiência produtiva.

Esses resultados evidenciam a importância do aquecimento proporcionado pelo sistema tambor + campânula, que, apesar de manter a temperatura na faixa de conforto somente em alguns horários do dia, foi superior aos demais sistemas de aquecimento.

$\mathrm{Na}$ terceira semana de vida das aves, não houve diferença na conversão alimentar, entretanto a eficiência produtiva foi maior nas aves mantidas nos sistemas de campânulas a gas e de tambor+campânula.

A temperatura ambiente, por afetar a temperatura corporal da ave, é um dos fatores que influenciam a atividade enzimática das aves (Acamovic \& McCleary, 1996). Até o período de 14-18 dias, o complexo enzimático das aves não está totalmente desenvolvido. As enzimas são eficientes catalisadores em sistemas biológicos (Stryer, 1995), tornando os nutrientes mais disponíveis para o animal e suplementando a produção de enzimas endógenas do animal (Strada et al., 2005)

Na quarta semana, as aves mantidas no sistema de tambor + campânula apresentaram a melhor conversão alimentar e maior eficiência produtiva. A partir da terceira semana de vida das aves, os sistemas de aquecimento não foram utilizados. No final da quarta semana, as aves mantidas no sistema de tambor + campânula apresentaram menor consumo total de ração, maior ganho de peso, melhor conversão alimentar e maior eficiência produtiva.

O melhor desempenho zootécnico das aves mantidas no sistema tambor + campânula está relacionado ao maior

Tabela 1 - Desempenho e índice de eficiência produtiva de pintos de corte nas quatro primeiras semanas de vida em três sistemas de aquecimento

\begin{tabular}{|c|c|c|c|}
\hline \multirow[t]{2}{*}{ Semana } & \multicolumn{3}{|c|}{ Consumo de ração (kg/ave) } \\
\hline & Fornalha a lenha & Campânulas infravermelhas & Tambor + campânulas \\
\hline 1 & $0,196 a$ & $0,190 \mathrm{a}$ & $0,185 a$ \\
\hline 2 & $0,553 a$ & $0,535 b$ & $0,536 b$ \\
\hline 3 & $0,663 b$ & $0,681 \mathrm{a}$ & $0,659 b$ \\
\hline 4 & $0,707 a$ & $0,715 a$ & $0,670 \mathrm{~b}$ \\
\hline \multirow[t]{2}{*}{ Total } & 2,119 & 2,121 & 2,050 \\
\hline & \multicolumn{3}{|c|}{ Ganho de peso $(\mathrm{kg})$} \\
\hline 1 & $0,111 \mathrm{a}$ & $0,112 \mathrm{a}$ & $0,116 \mathrm{a}$ \\
\hline 2 & $0,233 b$ & $0,234 b$ & $0,255 a$ \\
\hline 3 & $0,380 \mathrm{~b}$ & $0,405 a$ & $0,394 \mathrm{ab}$ \\
\hline 4 & $0,440 \mathrm{ab}$ & $0,431 b$ & $0,452 \mathrm{a}$ \\
\hline \multirow[t]{2}{*}{ Total } & 1,164 & 1,182 & 1,217 \\
\hline & \multicolumn{3}{|c|}{ Conversão alimentar } \\
\hline 1 & $1,77 \mathrm{a}$ & $1,70 \mathrm{ab}$ & $1,60 \mathrm{~b}$ \\
\hline 2 & $2,37 \mathrm{a}$ & $2,28 a$ & $2,10 \mathrm{~b}$ \\
\hline 3 & $1,75 \mathrm{a}$ & $1,68 a$ & $1,69 a$ \\
\hline 4 & $1,61 b$ & $1,66 \mathrm{a}$ & $1,48 b$ \\
\hline \multirow[t]{2}{*}{ Total } & 1,82 & 1,79 & 1,68 \\
\hline & \multicolumn{3}{|c|}{ Índice de eficiência produtiva } \\
\hline 1 & $447 c$ & $468 \mathrm{~b}$ & $499 a$ \\
\hline 2 & $238 b$ & $248 b$ & $278 a$ \\
\hline 3 & $318 b$ & $339 a$ & $341 \mathrm{a}$ \\
\hline 4 & $355 b$ & $348 b$ & $400 \mathrm{a}$ \\
\hline Total & 298 & 311 & 338 \\
\hline
\end{tabular}

Médias seguidas de uma mesma letra na linha não apresentaram diferença significativa a 5\% de probabilidade pelo teste Tukey. 
conforto térmico ambiental proporcionado pelo sistema de aquecimento. Na primeira semana de vida, as aves mantidas no sistema de campânulas a gás apresentaram os menores valores percentuais de mortalidade (Tabela 2). Nas segunda e terceira semanas de vida, não houve diferença na taxa de mortalidade entre os sistemas, mas, na quarta semana, as maiores taxas de mortalidade total foram observadas no sistema de aquecimento com fornalha a lenha e as menores taxas no sistema de campâ-nulas a gás. Esses dados indicam que a mortalidade não foi influenciada pelas temperaturas do ar no ambiente interno. Mortalidade de até 3\% em frangos de corte pode ser considerada normal, mas deve ser um alerta quando ultrapassar esses valores (Englert, 1998).

O consumo de água pelas aves na primeira semana de vida não foi influenciado pelos sistemas de aquecimento. As aves, sob estresse por frio, tendem a ingerir menor quantidade de água, entretanto, o menor consumo de água tem efeito direto no consumo de ração.

Na segunda semana de vida, as aves mantidas no sistema de aquecimento com campânulas a gás ingeriram menor quantidade de água, enquanto, na terceira semana de vida, as aves mantidas nesse sistema ingeriram maior quantidade de água. Segundo Cony \& Zocche (2004), ambientes mais aquecidos induzem maior ingestão de água pelas aves, pois a água é essencial nos mecanismos resfriatórios (perda calórica) envolvidos na termorregulação.

A taxa de crescimento inicial da ave pode ser afetada pelo consumo de água, assim como pela qualidade e quantidade de alimento, o nível de enzimas pancreáticas e intestinais, a área de superfície do trato gastrintestinal, os transportadores de nutrientes e a digestibilidade dos nutrientes (Dibner, 1996).

Na eclosão, o sistema digestivo da ave está anatomicamente completo, mas sua capacidade funcional de digestão e absorção ainda é limitada se comparado à de aves adultas (Maiorka et al., 2002). Assim, na pós-eclosão, o trato gastrintestinal sofre grandes alterações, como maturação funcional do intestino, que envolve mudanças morfológicas e fisiológicas que proporcionam aumento na área de superfície de digestão e de absorção. A alteração morfológica mais significativa é o aumento no comprimento do intestino, na altura e densidade dos vilos e no número de enterócitos, células caliciformes e células enteroendócrinas (Maiorka et al., 2002).

A pouca demanda por água pode estar relacionada ao pequeno desenvolvimento dos enterócitos nas aves nos primeiros dias de vida, que consequentemente realizam menor tunorver celular, gerando menor gasto energético e de água. Assim, aves mantidas em ambientes fora da zona de conforto térmico podem ter comprometidos os mecanismos digestivos e de absorção.

Na quarta semana de vida das aves, o menor consumo de água foi observado no sistema de tambor + campânula. Ao final das quatro semanas de vida, de forma geral, houve tendência de maior consumo de água entre as aves mantidas no sistema tambor + campânula, que proporcionou maior temperatura do ar.

Tabela 2 - Mortalidade (\%) e consumo de água (litros/ave) nas quatro primeiras semanas de vida de pintos de corte criados com três sistemas de aquecimento

\begin{tabular}{|c|c|c|c|c|c|c|}
\hline \multirow[t]{3}{*}{ Semanas } & \multicolumn{3}{|c|}{ Mortalidade (\%) } & \multicolumn{3}{|c|}{ Consumo de água (litros) } \\
\hline & \multicolumn{6}{|c|}{ Sistemas de aquecimento } \\
\hline & $\begin{array}{c}\text { Fornalha } \\
\text { a lenha }\end{array}$ & $\begin{array}{l}\text { Campânulas } \\
\text { infravermelhas }\end{array}$ & $\begin{array}{c}\text { Tambor }+ \\
\text { campânulas }\end{array}$ & $\begin{array}{c}\text { Fornalha } \\
\text { a lenha }\end{array}$ & $\begin{array}{l}\text { Campânulas } \\
\text { infravermelhas }\end{array}$ & $\begin{array}{c}\text { Tambor + } \\
\text { campânulas }\end{array}$ \\
\hline 1 & $1,29 a$ & $0,81 b$ & $1,13 \mathrm{a}$ & $0,021 \mathrm{a}$ & $0,017 \mathrm{a}$ & $0,032 \mathrm{a}$ \\
\hline 2 & $0,29 a$ & $0,31 \mathrm{a}$ & $0,32 \mathrm{a}$ & $0,085 a$ & $0,059 b$ & $0,102 \mathrm{a}$ \\
\hline 3 & $0,39 a$ & $0,33 a$ & $0,30 \mathrm{a}$ & $0,148 b$ & $0,121 b$ & $0,170 \mathrm{a}$ \\
\hline 4 & $0,87 a$ & $0,61 \mathrm{ab}$ & $0,53 b$ & $0,1901 \mathrm{a}$ & $0,176 \mathrm{a}$ & $0,159 b$ \\
\hline Total & 2,84 & 2,06 & 2,28 & 0,444 & 0,373 & 0,463 \\
\hline
\end{tabular}

Médias seguidas de mesma letra na linha não apresentaram diferença significativa a 5\% de probabilidade pelo teste Tukey.

\section{Conclusões}

O sistema de aquecimento conjugando tambores e campânulas é mais eficiente dos sistemas analisados, pois mantém o aviário em melhores condições de bem-estar térmico para aves de corte na primeira e segunda semanas de vida, o que proporciona melhor desempenho produtivo, por reduzir o estresse por frio.

\section{Referências}

ABREU, P.G.; BAETA, F.C.; ABREU, V.M.N. et al. Desempenho produtivo e bioeconômico de frangos de corte criados em diferentes sistemas de aquecimento. Revista Brasileira de Zootecnia, v.29, n.1, p.159-167, 2000.

ABREU, P.G.; ABREU, V.M.N. Caracterização dos principais sistemas de aquecimentos para aves. Concórdia: Embrapa Suínos e Aves, 2002. 8p. (Circular Técnica).

ACOMOVIC, T.; MC CLEARY, B.V. Optimising the response. Feed Mix, v.4, n.4, p.14-19, 1996. 
BAÊTA, F.C.; SOUZA, C. F. Ambiência em edificações rurais conforto animal. Viçosa, MG: Editora UFV, 1997. 246p.

BAIÃO, N.C.; CANÇADO, S.V. Efeito do intervalo entre o nascimento e o alojamento de pintos sobre o desempenho dos frangos. Arquivo Brasileiro de Medicina Veterinária e Zootecnia, v.50, p.191-194, 1998.

BUTCHER, G.D.; NILIPOUR, A.H. Broiler management - The first 24 hours. Gainesville: University of Florida - Institute of Food and Agricultural Sciences, 2002. 4p.

CONY, A.V.; ZOCCHE, A.T. Equipamentos para fornecimento de ração e água. In: MENDES, A.A.; NÄÄS, I.A.; MACARI, M. (Eds.) Produção de frangos de corte. Campinas: Fundação Apinco de Ciência e Tecnología Avícolas, 2004. p.97-106.

CRITCHFIELD, H.J. General climatology. Englewood Cliffs: Prentice-Hall, 1974. 447p.

CURTIS, S.E. Environmental management in animal agriculture. Ames: The Iowa State University Press, 1983. 409p.

DIBNER, J. Nutritional requirements of young poultry. In: ARKANSAS NUTRITON CONFERENCE, 1996, Fayetteville. Proceedings... Fayetteville: Arkansas Poultry Federation, 1996. p.15-27.

ENGLERT, S.I. Avicultura: tudo sobre raças, manejo e nutrição. 7.ed. Guaíba: Agropecuária, 1998. 238p.

FARIA FILHO, D.E.; ROSA, P.S.; FIGUEIREDO, D.F. et al. Dietas de baixa proteína no desempenho de frangos criados em diferentes temperaturas. Pesquisa Agropecúaria Brasileira, v.41, n.1, p.101-106, 2006.

FERREIRA, R.A. Maior produção com melhor ambiente para aves, suínos e bovinos. Viçosa, MG: Aprenda Fácil, 2005. 371p.

FRANCO, J.L.K. FRUHAUFF, M.E.V. Manejo para o controle de ascite, síndrome da morte súbita, stress por calor e coccidiose. Campinas: Fundação Apinco de Ciência e Tecnología Avícolas, 1997. p.121-133

FUNCK, S.R.; FONSECA, R.A. Avaliação energética e de desempenho de frangos com aquecimento automático a gás e a lenha. Revista Brasileira de Engenharia Agrícola e Ambiental, v.12, n.1, p.91-97, 2008

FURLAN, R.L. Influência da temperatura na produção de frangos de corte. In: SIMPÓSIO BRASIL SUL DE AVICULTURA, 6., 2006, Chapecó. Anais... Chapecó, 2006 (CD-ROM).

LANA, G.R.Q.; ROSTAGNO, H.S.; ALBINO, L.F.T. et al. Efeito da temperatura ambiente e da restrição alimentar sobre o desempenho e a composição da carcaça de frangos de corte. Revista Brasileira de Zootecnia, v.29, n.4, p.1117-1123, 2000.

MAIORKA, A.; MACARI, M.; FURLAN, R.L. et al. Fisiologia aviária aplicada a frangos de corte. Jaboticabal: FUNEP/ UNESP, 2002. p.113-123.

MACARI, M.; FURLAN, R.L.; GONZALES, E. Fisiologia aviária aplicada a frangos de corte. Jaboticabal: FUNEP, 1994. 296p.

MACARI, M.; FURLAN, R.L.; MAIORKA, A. Aspectos fisiológicos e de manejo para manutenção da homeostase térmica e controle de síndromes metabólicas. In: MENDES,
A.A.; NÄÄS, I.A.; MACARI, M. (Eds.) Produção de frangos de corte. Campinas: Fundação Apinco de Ciência e Tecnología Avícolas, 2004. p.137-155.

MAXWELL, M.H.; ROBERTSON, G.W. Vision panorámica de la ascitis en pollos en el mundo. Revista Industria Avícola, p.14 25, 1997.

McDOWELL, R.E. Bases biológicas de la producción animal en zonas tropicales. Zaragoza: Acribia, 1974. p.692.

MEDEIROS, M.M.; BAETA, F.C.; OLIVEIRA, R.F.M. et al. Efeitos da temperatura, umidade relativa e velocidade do ar em frangos de corte. Engenharia na Agricultura, v.13, n.4, p.277-286, 2005.

MICKELBERRY, W.C.; ROGLER, J.C.; STADELMAN, W.J. The influence of dietary fat and environmental temperature upon chick growth and carcass composition. Poultry Science, v.45, p.313-321, 1966.

MILLER, G. The first two weeks: a critical time. Quarterly Publication of Cobb-Vantress, v. 4, n.2, p.1-4, 1996.

NÄÄS, I.A.; MIRAGLIOTA, M.Y.; ARADAS, M.E.C. et al.

Ambiência na produção de aves em clima tropical. In: SILVA, I.J.O. (Ed.) Ambiência na produção de aves em clima tropical. 1.ed. Piracicaba, 2001. p.50-92.

OLIVEIRA, R.F.M.; DONZELE, J.L.; ABREU, M.L.T. et al. Efeitos da temperatura e da umidade relativa sobre o desempenho e o rendimento de cortes nobres de frangos de corte de 1 a 49 dias de idade. Revista Brasileira de Zootecnia, v.35, n.3, p.797-803, 2006

REECE, F.N.; LOTT, B.D. Mathematical model of broiler chicken houses. In: INTERNACIONAL LIVESTOCK ENVIRONMENT SYMPOSIUM, 2., 1982, Ames. Anais... Ames: American Society of Agricultural Engineers, p.241-243, 1982.

STRADA, E.S.O.; ABREU, R.D.; OLIVEIRA, G.J.C. et al. Uso de enzimas na alimentação de frangos de corte. Revista Brasileira de Zootecnia, v.34, n.6, p.2369-2375, 2005 (supl.)

STRYER, L. Bioquímica. 4.ed. Rio de Janeiro: Guanabara Koogan, 1995. 1000p.

TEETER, R.G; SMITH, M. High chronic ambient temperature stress effects on broiler acid-base balance and their response to supplemental ammonium chloride potassium chloride, and potassium carbonate. Poultry Science, v. 65, n.9, p.1777-1781, 1986.

TINÔCO, I.F.F.; FIGUEIREDO, J.L.A.; SANTOS, R.C. et al. Placas porosas utilizadas em sistemas de resfriamento evaporativo. Revista Engenharia na Agricultura, v.12, n.1, p.17-23, 2004

TINÔCO, I.F.F. Avicultura industrial: novos conceitos de materiais, concepções e técnicas construtivas disponíveis para galpões avícolas brasileiros. Revista Brasileira de Ciência Avícola, v.3, n.1, p.1-26, 2001.

TINÔCO, I.F.F. Estresse calórico: meios artificiais de condicionamento. In: SIMPÓSIO INTERNACIONAL DE AMBIÊNCIA E INSTALAÇÕES NA AVICULTURA INDUSTRIAL, 1995, Campinas. Anais... Campinas: Sociedade Brasileira de Engenharia Agrícola, 1995. p.99-108. 